\title{
ОСОБЕННОСТИ РЕМОДЕЛИРОВАНИЯ ЛЕВОГО ЖЕЛУДОЧКА У ПАЦИЕНТОВ С ТИРЕОТОКСИКОЗОМ В СОЧЕТАНИИ С ИШЕМИЧЕСКОЙ БОЛЕЗНЬЮ СЕРДЦА И ХРОНИЧЕСКОЙ СЕРДЕЧНОЙ НЕДОСТАТОЧНОСТЬЮ
}

\author{
Пащенко Е.В., Чесникова А.И., Кудинов В.И., Терентьев В.П., Ланкина М.С.
}

ФГБОУ ВО «Ростовский государственный медицинский университет» Минздрава России, г. Ростов-на-Дону, Россия

ЦЕЛЬ: выявить особенности ремоделирования левого желудочка (ЛЖ) у больных с тиреотоксикозом на фоне ишемической болезни сердца (ИБС) и хронической сердечной недостаточности (ХСН).

МАТЕРИАЛЫ И МЕТОДЫ: В исследование включили 81 пациента с тиреотоксикозом (диффУзНЫЙ токсический зоб, функциональная автономия на фоне узлового/многоузлового зоба), средний возраст составил $58,6 \pm 6,2$ лет. Всех больных распределили на 3 группы: основная - 25 больных с тиреотоксикозом, ИБС и клиническими признаками ХСН II-III функционального класса (ФК), 1-я группа сравнения - 30 пациентов с тиреотоксикозом без сердечно-сосудистых заболеваний (СС3), 2-я группа сравнения - 26 пациентов с тиреотоксикозом и ИБС, без симптомОв и клинических признаков ХСН. Всем пациентам проводилась стандартная терапия тиреостатиком. Лечение ИБС и ХСН проводилось в соответствии с современными рекомендациями. Определяли показатели свободного трийодтиронина $\left(\mathrm{T}_{3}\right)$ и свободного тетрайодтиронина $\left(\mathrm{T}_{4}\right)$, тиреотропного гормона (ТTГ); ЭхоКГ и допплерЭхоКГ исследования выполняли на ультразвуковом аппарате MyLab70 («Esaote», Италия). На основании показателей индекса массы миокарда ЛЖ и индекса относительной толщины стенки определяли типы ремоделирования ЛЖ.

PЕЗУЛЬТАТЫ: У пациентов с тиреотоксикозом без ССЗ нормальная геометрия ЛЖ (НГЛЖ) была выявлена лишь в 46,7\% случаев, на долю концентрической гипертрофии (КГЛЖ) и эксцентрической гипертрофии (ЭГЛЖ) пришлось по 13,3\% и 10,0\% соответственно, а преобладало в этой группе концентрическое ремоделирование (КРЛЖ) - у 30\% больных. У пациентов с тиреотоксикозом и ИБС без клинических признаков ХСН НГЛЖ выявлена в 3,8\% случаев, КРЛЖ - только в 11,5\%, а самым частым вариантом патологического ремоделирования была КГлЖ - в 73,1\% случаев. У больных основной группы (с тиреотоксикозом на фоне ИБС и ХСН) гипертрофия ЛЖ была выявлена в 100\% случаев. Следует отметить, что ремоделирование ЛЖ у пациентов этой группы было представлено лишь двумя типами: концентрическая и эксцентрическая гипертрофия ЛЖ, причем достоверно преобладала КГЛЖ - в 84\% случаев $(p=0,01)$.

ВЫВОдЫ: таким образом, у пациентов с тиреотоксикозом без СС3 гипертрофия ЛЖ выявлена в 53,3\% случаев, преимущественно за счет КРЛЖ (30\%). У больных с тиреотоксикозом на фоне ИБС и ХСН выявлены прогностически наиболее неблагоприятные типы ремоделирования ЛЖ: КГЛЖ и ЭГЛЖ, что определяет особенности ремоделирования ЛЖ в условиях коморбидной патологии. 